\title{
A CONTROL AND SYSTEMS ANALYSIS \\ OF ARTIFICIAL INSTREAM AERATION
}

\author{
P.G. Whitehead* \\ Control and Systems Group \\ Department of Engineering \\ University of Cambridge \\ England
}

ABSTRACT

The identification and estimation of discrete-time models of BOD-DO

(Biochemical Oxygen Demand-Dissolved Oxygen) in river systems is considered using a multivariable extension of the instrumental variable approximate maximum likelihood techniques of time series analysis. The dynamic water quality models relate water quality at specific points on the river and are used in a design study to evaluate the performance of artificial aerators in the River Cam. Operating schemes are developed which utilise closed loop state variable feedback control and feedforward control to maintain adequate levels of dissolved oxygen in the river.

1.

Introduction

In 1972 a programme of research was initiated in the Control Group at Cambridge in collaboration with the Great Ouse River Division of the Anglian Water Authority and the Department of the Environment. The research has been directed towards obtaining robust, low order models of water quality states in river systems; models that are dynamic and describe the day to day variation in water quality and are stochastic and account for the inevitable uncertainties associated with the system. At the same time the models are designed to be of practical utility and one such design application is described in this paper for the control of oxygen regimes in river systems.

The steadily deteriorating condition of the River Cam in South East England in recent years has led to frequent summer fish mortalities, a condition that may be alleviated in the long term by improved effluent treatment. In the short term, however, artificial instream aeration is considered a viable alternative providing an inexpensive means of improving oxygen regimes in the river. As shown in Figure 1, the effluent from Cambridge Sewage Works produces an oxygen sag, the minimum of which occurs approximately four kilometres downstream. The objective of the aerator system is to raise the level of the dissolved oxygen in the river in order to prevent the dangerously low levels of oxygen at the minimum. The performance of the aerators depends largely on the day to day variations of watex quality and environmental conditions and it is necessary therefore toidentify and estimate a dynamic water quality model for this stretch of the River Cam prior to the design of a control strategy.

*Paul Whitehead is a member of Wolfson College 

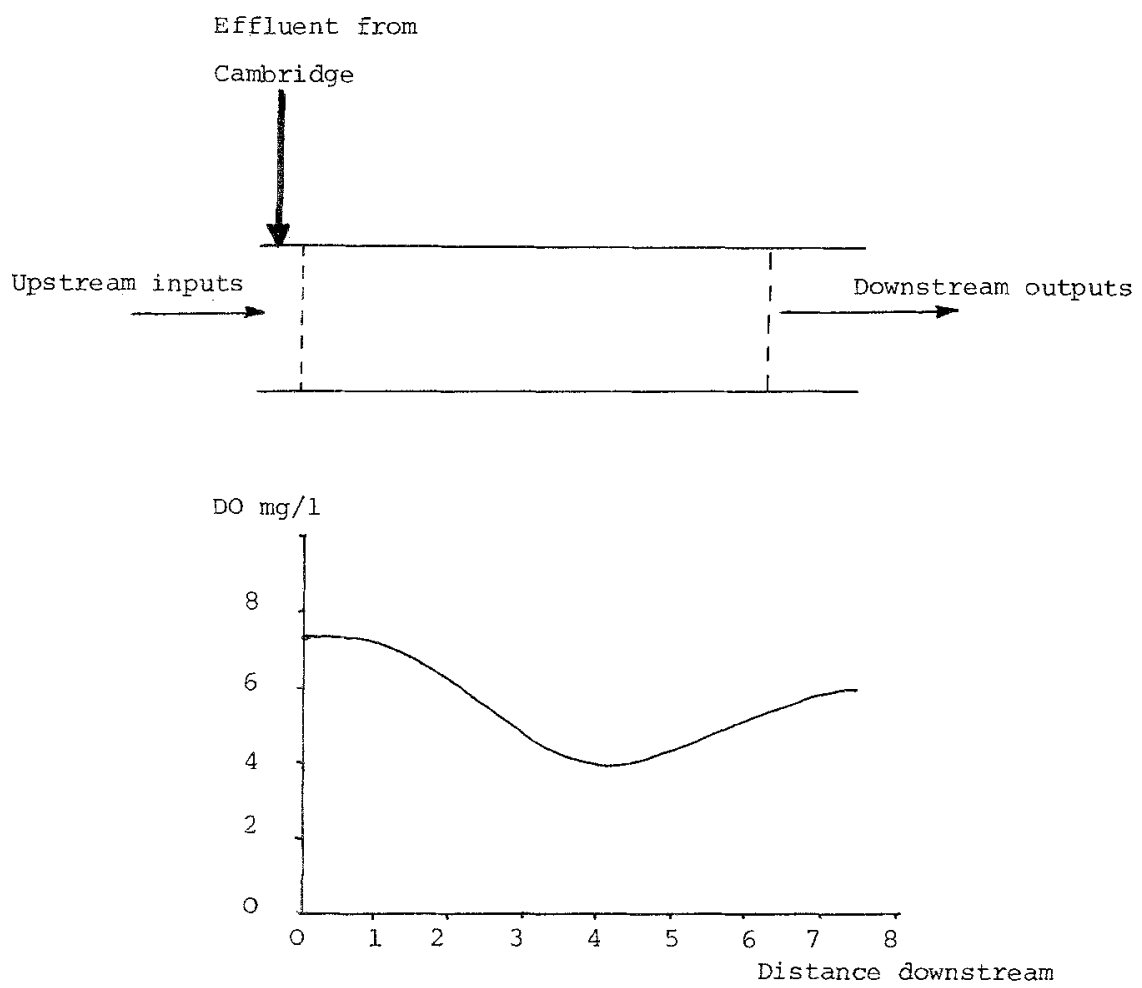

Figure 1 River reach downstream of Cambridge and the Dissolved Oxygen profile. 
2. Identification and Estimation of BOD-DO Models

During the early stages of the river system modelling exercises both for the River Cam (see Beck and Young 1974) and for another river, the Bedford Ouse (see Whitehead and Young 1974), the extended Kalman filter (EKF) has proved to be a flexible tool with which to identify suitable dynamic water quality model structures. An initial model is formulated based on some heuristic feeling or physico-chemical understanding of the system, and the EKF is then used to test the efficacy of these models and, where necessary, to supplement the basic model with additional terms to account for disturbances (Beck and Young 1975).

For example by considering bias terms on the system equations as random variables, it was possible to obtain recursive estimates of their variation over the sample period. These estimates showed most variation during periods of prolonged sunlight and, as a result, it was concluded that the discrepancies between the model response and the observed data was most probably due to photosynthetic effects.

Further investigation revealed that in the case of the River Cam, the release of oxygen by photosynthetic activity on algae populations and the BOD load exerted by the mass deaths of algae were both suitably accounted for in terms of a pseudo-empirical relationship dependent upon temperature and sunlight conditions. In order to estimate the effects of photosynthetic activity in the Ouse, chlorophyll A data was recorded in addition to temperature and sunlight and an alternative empirical oxygen production equation was developed which incorporated the algal effects directly. A complete statistical analysis of the BOD-DO model using a continuous discrete version of the EKF is described by Beck and Young (1974).

The identification of the model structure represents an important phase in the analysis and the flexibility of the EKF is an enormous advantage during this initial stage. However, the flexibility can lead to inefficiency, both computation and statistical, when used to estimate the parameters that characterise the identified model structure.

An approach to multivariable system parameter estimation which is both more systematic than the EKF and appears to provide a considerable improvement in statistical efficiency involves a multivariable extension of the Instrumental Variable - Approximate Maximum Likelihood (IVAML) method of time-series analysis, previously applied to single input, single output model estimation (Young 1974, Young et al, 197I). The approach is restricted to discrete time, vector matrix equations and requires that most of the state vector is available for measurement.

Consider the following discrete-time, state-space representation of a multivariable (mu1ti-input, multi-output), linear dynamic system,

$$
\underline{x}_{k}=A_{-k-1}+B \underline{u}_{k-1}
$$


where $\underline{x}_{k}=\left[\begin{array}{llll}x_{1 k} & x_{2 k} & \cdots & x_{n k}\end{array}\right]^{T}$ is an $n$ dimensional vector of state variables that characterise the system at the $k$ th instant of time, $\underline{u}_{k}=\left[\begin{array}{llll}u_{1 k} & u_{2 k} & \cdots & u_{m k}\end{array}\right]^{T}$ is an $m$ dimensional vector of deterministic input variables, also sampled at the $\mathrm{kth}$ time instant, while $A$ and $B$ are, respectively, $n \times n$ and $n \times m$ matrices with elements

$a_{i j}(i, j=1,2, \ldots, n)$ and $b_{i j}(i=1,2, \ldots, n ; j=1,2, \ldots, m)$.

Suppose now that each element $x_{i k}$ of the state vector $\underline{x}_{k}$ is available for measurement but is contaminated by a zero mean lumped noise disturbance $\xi_{i k}$ which is assumed to include the effects of all stochastic inputs and other disturbances as

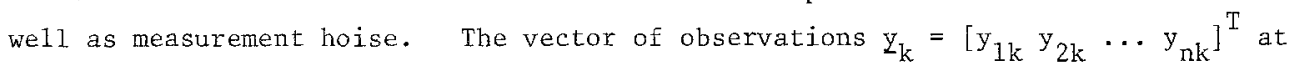
the kth instant is then defined by

$$
\underline{y}_{k}=\underline{x}_{k}+\underline{\xi}_{k}
$$

Here $\xi_{k}=\left[\xi_{1 k} \xi_{2 k} \ldots \xi_{n k}\right]^{T}$ is the $n$ dimensional vector of the lumped noise disturbances which is assumed to have the following statistical properties

$$
\mathbb{E}\left\{\underline{\xi}_{k}\right\}=0 ; E\left\{\underline{\xi}_{k} \underline{\xi}_{k}^{T}\right\}=Q ; E\left\{\underline{\xi}_{k} \underline{u}_{j}^{T}\right\}=0 \text {, for all } k, j
$$

In other words, the noise disturbances are assumed to be zero mean random variables which may, in general, be both serially correlated in time and correlated with each other at the same instant of time, but which are completely uncorrelated with the deterministic input variables that compose the input vector $\underline{u}_{k}$.

Substituting from equation (2) into (1) we obtain the following relationship between the measured variables

$$
\mathrm{y}_{\mathrm{k}}=\mathrm{Ay}_{\mathrm{k}-1}+\mathrm{Bu}_{\mathrm{k}-1}+\underline{\mathrm{n}}_{\mathrm{k}}
$$

where $\eta_{k}$ represents the combined effects of the system stochastic disturbances and is defined as

$$
\underline{n}_{k}=\underline{\xi}_{k}-A \underline{\xi}_{k-1}
$$

In practice a discrece time model such as (1) could be obtained either by direct analysis of the physical system in discrete time terms, by transformation of an equivalent continuous-time state-space model using standard methods of transformation (Dorf, 1965), or by a combination of both.

The water quality model developed for the River Cam and the Bedford Ouse is in the form of equation (1) with the multivariable model describing the relationships between Biochemical oxygen Demand (BOD) and Dissolved Oxygen (DO) at the output of a single reach in a non-tidal river system. This model takes the form of two coupled first order equations and can be written as

BOD: $\quad \mathrm{x}_{1 \mathrm{k}}=\mathrm{k}_{1} \frac{\mathrm{Vm}}{\mathrm{Q}_{\mathrm{k}-1}} \mathrm{x}_{1, \mathrm{k}-1}+\mathrm{k}_{2} \mathrm{u}_{1, \mathrm{k}-1}+\mathrm{k}_{3} \mathrm{~S}_{\mathrm{k}-1}$

DO:

$$
x_{2 k}=k_{4} x_{1, k-1}+k_{5} \frac{V m}{Q_{k-1}} x_{2, k-1}+k_{6} u_{2, k-1}+k_{7} s_{k-1}+k_{8} c_{s, k-1}
$$


where $\mathrm{x}_{1}$ is the BOD at the output of the reach, which can be considered as an aggregate or macro measure of the oxygen absorbing potential of substances in the stream (such as decaying organic material from effluent discharges), and is defined as the oxygen absorbed in $\mathrm{mg} l^{-1}$ over a five day period by a sample of river water in the absence of light at a constant temperature of $20^{\circ} \mathrm{C}$;

$\mathrm{x}_{2}$ is the Do at the output of the reach (mg $2^{-1}$ );

$Q$ is the volumetric flow rate in the stream $\left(\mathrm{m}^{3}\right.$ day $\left.{ }^{-1}\right)$;

$\mathrm{v}_{\mathrm{m}}$ is the mean volumetric hold-up in the reach $\left(\mathrm{m}^{3}\right)$;

$u_{1}$ is the input BOD from the previous upstream reach in the river system $\left(\mathrm{mg} e^{-1}\right)$;

$\mathrm{u}_{2}$ is the input DO from the previous upstream reach (mg $l^{-1}$ );

$\mathrm{S}$ is the term dependent upon sunlight hours and chlorophyl A level to account for photosynthetic effects such as algal growth and decay;

$\mathrm{C}_{\mathrm{s}}$ is the saturation concentration of $\mathrm{DO}\left(\mathrm{mg} l^{-1}\right)$;

and

$$
\begin{aligned}
& k_{1}, k_{2}, \ldots, k_{8} \text { are coefficients or parameters which will be either constant } \\
& \text { or slowly time-variable depending on the period of observation. }
\end{aligned}
$$

Equations (6) and (7) may be easily written in the vector matrix form of equation (1) by defining the matrices $(A ; B)$ and the vectors $\left(\underline{x}_{k} ; \underline{u}_{k}\right)$ in the following manner:

$$
\begin{aligned}
& A=\left[\begin{array}{ccc}
k_{1} \frac{v_{m}}{a_{k-1}} & 0 \\
k_{4} & k_{5} & \frac{v_{m}}{Q_{k-1}}
\end{array}\right] ; \quad B=\left[\begin{array}{llll}
k_{2} & 0 & k_{3} & 0 \\
0 & k_{6} & k_{7} & k_{8}
\end{array}\right] ; \quad \underline{u}_{k}^{T}=\left[\begin{array}{lllll}
u_{1 k} & u_{2 k} & s_{k} & c_{s, k}
\end{array}\right] \\
& \underline{x}_{k}^{T}=\left[\begin{array}{lll}
x_{1 k} & x_{2 k}
\end{array}\right] ;
\end{aligned}
$$

Sampled values for both states can be obtained from a planned experiment: Do is easily measurable by an instream probe; BOD, on the other hand, is somewhat more difficult to estimate since a sample of river water must be kept in controlled conditions for 5 days, as indicated in its definition (indeed the measurement is sometimes termed "5 day BOD"). The resulting measurement equations can be written in the vector form (2) with the elements $y_{1 k}$ and $y_{2 k}$ of the vector $y_{k}$ denoting the BOD and DO observations, respectively, and with $\xi_{1 k}$ and $\xi_{2 k}$ denoting the effects of stochastic disturbances and unavoidable measurement noise.

The basic estimation problem posed by equations (1) and (2) is to use the noisy observations of the state variables given in (2) to obtain consistent 
estimates of the $n^{2}+n m$ parameters that characterise the $A$ and $B$ matrices in (1). In order to solve this problem we first note that the ith elemental row of the composite equation (3) can be written as

$$
y_{i k}=\underline{z}_{k}^{T} \underline{a}_{i}+\eta_{i k}
$$

where

$$
\begin{array}{r}
z_{-k}^{T}=\left[y_{1, k-1} y_{2, k-1} \ldots y_{n, k-1}, \ldots, u_{m, k-1}\right] \\
a_{i}=\left[a_{i l}, a_{i 2} \ldots a_{i n}, b_{i l}, \ldots, b_{i m}\right]^{T}
\end{array}
$$

and

$$
\eta_{i k}=\xi_{i k}-a_{i 1} \xi_{1, k-1}-, \ldots,-a_{i n} \xi_{n, k-1}
$$

Thus one simple approach to the problem of estimating the unknown parameters is to decompose the overall estimation problem into $n$ separate sub-problems, each defined in terms of an estimation model such as (9) which is linear in an $n+m$ subset of the $n^{2}+n m$ unknown parameters.

In order to obtain a consistent estimate of the parameter vector $\underline{a}_{i}$ a least squares regression algorithm is modified using the instrumental variable approach described by Young (1970). A recursive algorithm is obtained in which the estimate $\hat{a}_{i k}$ after $k$ samples is obtained as the linear sum of the previous estimate $\hat{a}_{i, k-1}$ plus a corrective term based on new information $y_{i k}, z_{k}$ and $\hat{\hat{x}}_{-k}$, where $\hat{\underline{x}}_{k}$ is a vector of instrumental variables (see Young and whitehead 1974). The recursive estimation algorithm is of the following form.

$$
\hat{\underline{a}}_{i k}=\hat{a}_{i, k-1}-\underline{K}_{k}\left\{\underline{z}_{k}^{\mathrm{T}} \hat{\hat{a}}_{i, k-1}{ }^{-y}{ }_{i k}\right\}
$$

where $\mathrm{K}_{-\mathrm{k}}$ is a gain vector defined by

$$
\mathrm{K}_{\mathrm{k}}=\hat{\mathrm{P}}_{\mathrm{k}-1-\hat{x}_{\mathrm{k}}}\left[1+\underline{\mathrm{z}}_{\mathrm{k}}^{\mathrm{T}} \hat{\mathrm{p}}_{\mathrm{k}-1} \hat{\underline{x}}_{\mathrm{k}}\right]^{-1}
$$

and the matrix $\hat{\mathrm{P}}_{k}$ is obtained by a second recursive algorithm

$$
\hat{\mathrm{P}}_{\mathrm{k}}=\hat{\mathrm{P}}_{\mathrm{k}-1}-\hat{\mathrm{P}}_{\mathrm{k}-1-1} \hat{\mathrm{x}}_{\mathrm{k}}\left[1+\underline{\mathrm{z}}_{\mathrm{k}}^{\mathrm{T}} \mathrm{P}_{\left.\mathrm{k}-1-\hat{\mathrm{x}}_{\mathrm{k}}\right]}\right]^{-1} \underline{z}_{\mathrm{k}}^{\mathrm{T}} \hat{\mathrm{P}}_{\mathrm{k}-1}
$$

The problems of choosing suitable instrumental variable $\hat{\underline{x}}_{k}$ are discussed in detail by Young and Whitehead (1974) together with a discussion of the modelling problems associated with the noise vector $\eta_{i k}$.

The estimation algorithms have been applied to field data obtained from both the Bedford Ouse and the River Cam and a deterministic forecast of BOD and DO is given in Figure 2 for the reach of the Cam where the system model was estimated as

$x_{k}=\left[\begin{array}{cc}0.36 \frac{\mathrm{V}_{\mathrm{m}}}{\mathrm{Q}_{\mathrm{k}-1}} & 0 \\ -0.25 & -0.26 \frac{\mathrm{V}_{\mathrm{m}}}{\mathrm{Q}_{\mathrm{k}-1}}\end{array}\right] \mathrm{x}_{\mathrm{k}-1}+\left[\begin{array}{c}0.27 \\ 0.33\end{array}\right]\left[\begin{array}{c}\mathrm{L}_{\mathrm{k}-1} \\ \mathrm{C}_{\mathrm{k}-1}\end{array}\right]+\left[\begin{array}{c}0.43 \\ 0.84\end{array}\right] \mathrm{s}_{\mathrm{k}-1}+\left[\begin{array}{c}0 \\ 0.1\end{array}\right] \mathrm{C}_{\mathrm{s}_{k-1}}$ 

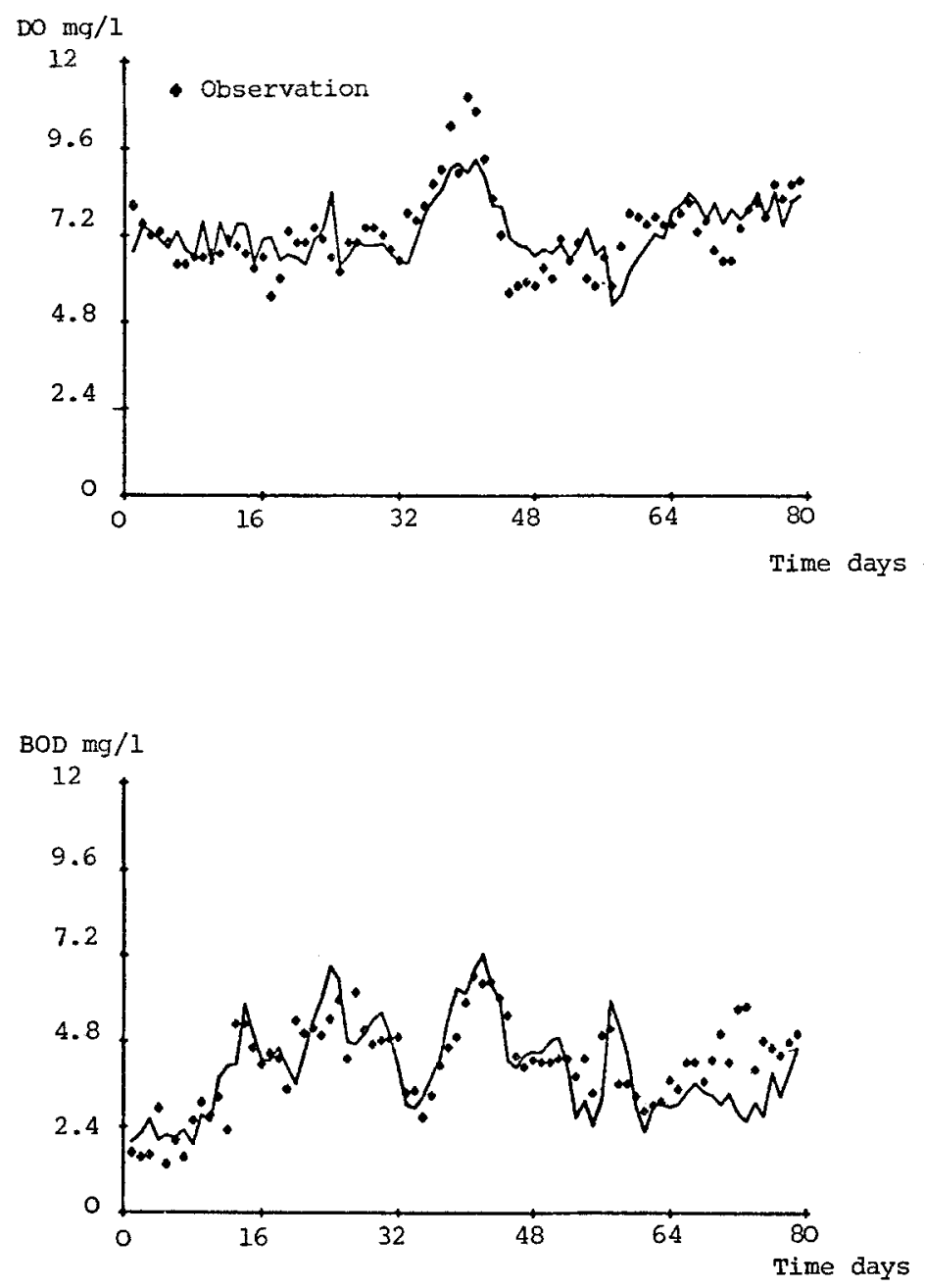

Figure 2 Discrete Time model simulation for BOD-DO on River Cam. 
This simple discrete time model adequately describes the dynamic behaviour of BOD and DO over the 80 day summer period in 1972 and may be used in an aerator design study.

3.

Techniques for Water Quality Control

Dynamic models have been used widely in the process industries for the design and evaluation of engineering systems from the operational management viewpoint. often complex chemical reactions have to be closely controlled in order to meet product specifications and, for example, it is possible by continuously monitoring a quality state downstream of a reactor, to detect any deviation from the specified desired level and take whatever remedial action is required to correct the situation. The idea of monitoring, detecting an error from a reference leve1 and then taking remedial action is, of course, closed loop control; the loop is closed either by the operational managers, who take a decision to change certain appropriate variables in the system or by automatic controllers which directly adjust the input control variables.

The design of automatic feedback control systems is aided considerably by a dynamic model of the system which can be used in place of the plant in an "off-line" design study. In this way experimentation on the plant, which may be both expensive and dangerous, can be avoided. Bearing in mind the experience of the Process Industries, it seems clear that feed back control is potentially an extremely useful technique in the water resource context.

One control problem of particular interest is the maintenance of dissolved oxygen levels in rivers immediately downstream of sewage outfalls. A recently formed Cam working party (1974), for instance, has the task of controlling dissolved oxygen in the River Cam downstream of Cambridge sewage works in order to prevent fish mortalities. Young and Beck (1974) have investigated two methods of maintaining the DO level in this reach of the Cam using either a variable effluent quality from the treatment plant or a variable effluent discharge rate into the river. For both control systems it was assumed that BOD information was nat available and that only the dissolved oxygen was continuously monitored at the downstream point. Such schemes are, however, high capital cost solutions requiring long term justification and, for full flexibility, the Water Authority may of ten have to look for lower cost, albeit temporary, alternatives.

on low-cost alcernative approach to the maintenance of dissolved oxygen levels in a river system is by artificial aeration using mechanical aerators. This has obvious practical advantages since it does not rely on purpose built treatment plants and avoids the high capital cost of building such plants. However, artificial aerators should always be viewed as a temporary solution since they cannot cope with a continually worsening effluent from an overloaded sewage works; indeed this may well tend to mask a slowly deteriorating situation. 
Artificial aeration of polluted rivers has been investigated both experimentally and theoretically by whipple et al (1970) and it has been used for some time in practical situations as a method of alleviating pollution problems. The principle is simply to increase the air-water interfacial area, either by the additional turbulence introduced by mechanical aerators or by the entrained bubbles generated by a diffuser, and thereby to increase the rate of transfer of oxygen from the air to the water.

If instream aeration is proposed as a short term solution to a particular river water quality problem then it is clearly desirable to have some form of control system to operate the aerators so as to maintain the desired level of Do. And it is for the design of such a control scheme that a dynamic model of BOD-DO can be of particular relevance.

4. An instream aeration control study on the Bedford-Ouse

Conventional controllers for aerator equipment utilise an upstream probe to monitor continuously dissolved oxygen. The aerator equipment is switched on immediately a low level of upstream Do is detected. This may not be satisfactory if high levels of BOD are present since it is the DO level downstream of the aerator that will tend to be depressed (i.e. fish mortalities occur at the minimum point of the dissolved oxygen sag which mught often occur downstream of the aerator). On the other hand a dissolved oxygen probe located close to the average minimum DO position would feedback information on the critical Do level and aerator operation would be on the basis of this measurement. The influence of upstream water quality is still important, however, since it gives prior warning of high BOD loads: the upstream Do probe measures this input disturbance and provides "feedforward" information to the controller.

A feedforward-feedback control strategy is shown on the left of the block diagram in Figure 3 where the gains $k_{1}, k_{2}$ and $k_{3}$ represent controller parameters; $\mathrm{k}_{1}$ influences the direct Do feedback, $\mathrm{k}_{2}$ is the gain on the integrated error between the dissolved oxygen and the reference level $\mathrm{y}_{\mathrm{r}}$ and $\mathrm{k}_{3}$ is the gain on the feedforward signal. The summation of these three effects is related to the oxygen input required at the aerators to maintain a constant level of dissolved oxygen at the downstream point. The controller gains affect the transient response of the system and therefore can be designed to meet certain specifications.

For instance, we would require a reasonably fast response to maintain good control but the effect of having large control gains consistent with such performance could be to produce an oscillatory response or large disturbances which would put the model states outside the range over which they have been estimated. Such non-1inear or oscillatory conditions are clearly not satisfactory.

There are several techniques for the design of "satisfactory" control systems (see Box and Jenkins, 1974 or Astrom, 1970) but one purely deterministic 


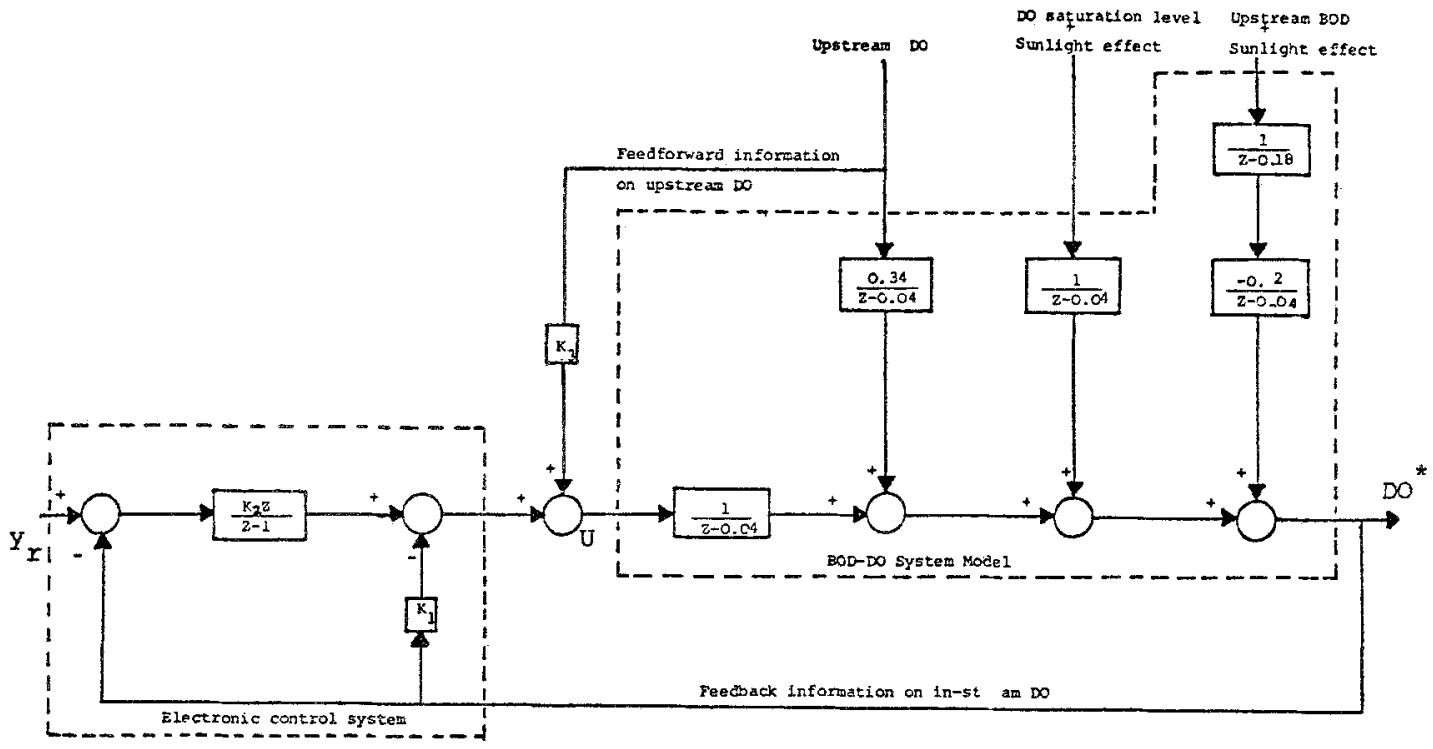

Figure 3. Block diagram of Ouse model and control scheme.

DO ${ }^{*}$ controlled downstream DO level

$\mathrm{u} D$ input at aerators

$y_{r} \quad$ DO reference level 
technique developed by Young and Willems (1972) is servomechanism "pole assignment". Here the control system gains are chosen to ensure that the dynamic modes of behaviour of the closed loop system are of a suitable frequency and damping; and at the same time, that the steady state or equilibrium characteristics are consistent with the specified "acceptable" levels of DO.

In discrete time terms, the servomechanism pole assignment technique has been described by Young and Beck (1974) and we shall consider it briefly for completeness.

Consider the discrete-time system described by the state equations

$$
\begin{aligned}
& \underline{\mathrm{x}}_{\mathrm{k}+1}=\mathrm{Fx}_{\mathrm{k}}+\mathrm{Gu}_{-\mathrm{k}} \\
& \mathrm{y}_{\mathrm{k}}=\mathrm{Cx}_{\mathrm{k}}
\end{aligned}
$$

where $\underline{x}_{k}$ represents the system states at time $k$ (i.e. downstream BOD and DO)

$u_{k}$ represents the control input vector at time $k$

$y_{k}$ represents the state observations at time $k$

F, G and $\mathrm{C}$ are matrices of coefficients.

In order to introduce an "integral of error" term between the desired reference level $[\mathrm{yr}]_{k+1}$ and the controlled state $\underline{\mathrm{y}}_{\mathrm{k}+1}$ an additional equation is adjointed to the system equations (see Young and Beck 1974)

$$
\underline{w}_{k+1}=\underline{w}_{k}+\mathrm{T}\left([\underline{y} r]_{k+1}-C_{\underline{k}+1}\right)
$$

We see that provided the system is stable so that a steady state exists then $\underline{\mathrm{w}}_{\mathrm{k}+1}=\underline{\underline{\mathrm{w}}}_{\mathrm{k}}$ and as desired $\underline{\mathrm{y}}_{\mathrm{k}}=\mathrm{C} \underline{\mathrm{x}}_{\mathrm{k}}=\underline{\underline{y}}_{\mathrm{r}}$.

On substituting from the system equations (10), we see that equation (11) becomes

$$
\underline{w}_{k+1}=\underline{w}_{k}+\mathrm{T}\left([\underline{y} r]_{k+1}-\mathrm{CF}_{-\mathrm{k}}-\mathrm{CGU}_{-\mathrm{k}}\right)
$$

The overall system equation is then obtained by combining the two equations (10) and (12) above as follows

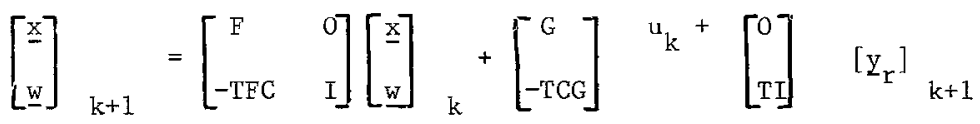

The state variable feedback control law is now defined as

$$
\begin{aligned}
& u=-\left(k_{1} x_{1 k}+k_{2} x_{2 k} \cdots k_{n} x_{n k}\right) \text { or in vector form } \\
& u=-k^{T} x_{k}
\end{aligned}
$$

where $k_{1}, k_{2} \ldots k_{n}$ are controller gains used to assign the poles of the closed loop system to arbitrary (within physical reason) positions inside the unit circle in 
the complex plane, and to provide reasonable closed loop control dynamics.

In the above context, the control problem of aerating the river reduces to a single variable problem on the DO state since the BOD state cannot be controlled by re-aeration and, for the purposes of control can be considered simply as an additional distrubance term.

Under this assumption the linear state variable feedback law equation (14) $u_{k}$ reduces therefore to

$$
u_{k}=-\left(k_{1} x+k_{2} w\right)
$$

with state variable feedback on the Do state, $x$, together with the integral error, w.

Evaluating equation (13) for the Bedford Ouse reach (see Whitehead and Young, 1974) for the summer condition of mean $\mathrm{v} / \mathrm{Q}=2.0$ gives

$$
\left[\begin{array}{c}
x_{k+1} \\
w_{k+1}
\end{array}\right]=\left[\begin{array}{rr}
0.04 & 0 \\
-0.04 & 1
\end{array}\right]\left[\begin{array}{l}
x_{k} \\
w_{k}
\end{array}\right]+\left[\begin{array}{c}
k^{T} \\
-k^{T}
\end{array}\right]\left[\begin{array}{l}
x_{k} \\
w_{k}
\end{array}\right]+\left[\begin{array}{l}
0 \\
1
\end{array}\right]\left[_{r}\right]_{k+1}
$$

which can be written concisely

$$
\left[\begin{array}{cc}
z-0.04+k_{1} & k_{2} \\
0.04-k_{1} & z-1-k_{2}
\end{array}\right]\left[\begin{array}{c}
x_{k} \\
w_{k}
\end{array}\right]=\left[\begin{array}{l}
0 \\
1
\end{array}\right] \quad\left[y_{r}{ }_{k+1}\right.
$$

where $Z$ is the $z$ transform or forward shift operator, i.e. $Z x_{k}=x_{k+1}$.

The closed loop characteristic equation can then be obtained in the usual manner (see Takahashi 1970) as the

$$
\begin{aligned}
& \operatorname{det}\left[\begin{array}{cc}
z-0.04+k_{1} & k_{2} \\
0.04-k_{1} & z-1-k_{2}
\end{array}\right]=0 \\
& \text { i.e. } z^{2}+z\left(k_{1}-k_{2}-1.04\right)+\left(0.04-k_{1}\right)=0
\end{aligned}
$$

The desired closed loop pole positions in the 2 plane can be obtained in various ways but here they were set at $-0.06 \pm 0.13$ in order to yield for a damping ratio of 0.7 and a natural frequency of $2 \mathrm{rad} / \mathrm{day}$. These pole positions give a characteristic equation of the form

$$
z^{2}+0.12+0.017
$$

and, equating the coefficients of (17) and (18), produces the following laws, which will theoretically ensure the desired closed loop pole positions.

$$
0.12=k_{1}-k_{2}-1.04
$$

and

$$
0.017=0.04-k_{1}
$$




$$
\begin{aligned}
& \text { giving } \\
& \qquad \begin{aligned}
\mathrm{k}_{1} & =0.023 \\
\mathrm{k}_{2} & =1.14
\end{aligned}
\end{aligned}
$$

At this stage we have defined the closed loop characteristics but we still require to minimise the input Do disturbance.

A possible deterministic method of minimising this unwanted disturbance is to insert into the system a feedforward branch whose input is the unwanted disturbance. The method is only applicable to those systems in which a disturbance can be physically detected but in the river system the upstream input DO may be measured continuously or discretely via an instream probe. The principle of invariance (D'Azzo and Houpis 1966) is used to determine the gain $k_{3}$ on the feedforward branch where $k_{3}$ is chosen to minimise the input Do effect. From Figure 3 we see that the Do disturbance is given by

$$
\mathrm{D}=\frac{0.34}{(\mathrm{Z}-0.04)}
$$

and, the total effect of the feedforward compensator $\mathrm{F}_{\mathrm{c}}$ is

$$
F_{c}=\frac{k_{3}}{(\mathrm{z}-0.04)}
$$

The effect of the observed disturbance will be cancelled if we set the compensation to

$$
F_{c}=\frac{-0.34}{(\mathrm{Z} 0.04)}
$$

i.e. $\quad k_{3}=-0.34$

Such deterministic feedforward control is particularly sensitive to errors in the model parameters and should, therefore, be used with caution in a practical situation; indeed the design should always be checked by extensive stochastic simulation prior to any attempt at implementation.

In the latter connection, it will be noted that following the lead of Young and Beck (1974) purely deterministic control system design has been considered here despite the fact that stochastic models are available. This was considered advisable in the first instance since it is simple and because it provides a reference against which to judge stochastic designs that may be conceived at a later stage. Too often in the current control theory oxientated world of control, "optimal" and complex solutions are considered first and, in consequence, simpler possibilities receive less than adequate attention.

Figure 4 shows the simulated response of the control system designed above to a step change in the reference level from six to seven $\mathrm{mg} / \mathrm{l}$ on day 15 ; immediately the error between the downstream DO and the reference level is observed the control signal increases and the instream po moves up to the new desired level 
Control input DO $\mathrm{mg} / \mathrm{I}$

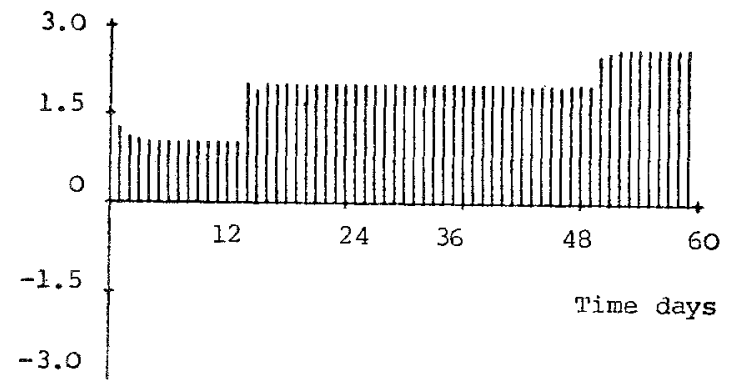

Controlied downstream $D O \mathrm{mg} / \mathrm{l}$

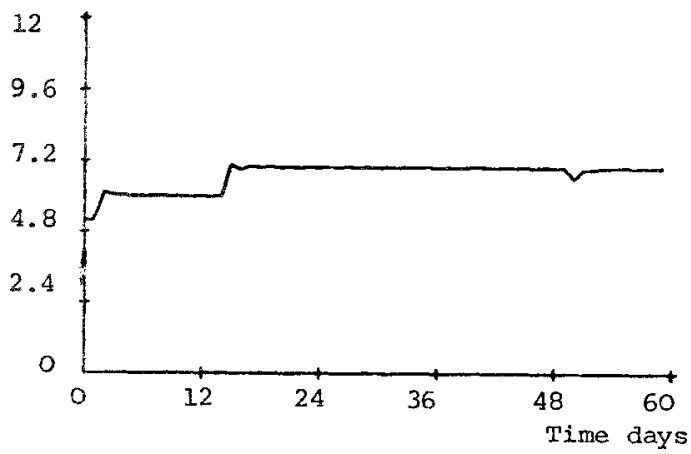

Pigure 4 Downstream DO and input control signal 
with a response speed defined by the control system design. On day 50 the response of the system to a step change of $3 \mathrm{mg} / 1$ in the BOD is shown; here the Do decreases initially but the controller acts to minimise the discrepancy from the desired level and the Do slowly recovers again in a manner defined by the control system design.

Figure 4 illustrates the control action with no additional distrubances, such as algal or sunlight effects. Figure 5, on the other hand, shows the simulated response of the hypothetical reaeration control system acting on the reach over a "typical" summer period based primarily on the 1973 data but assuming an additional BOD load of $5 \mathrm{mg} / 1$ in the river. With the Do desired reference level at $6 \mathrm{mg} / 1$, it is clear that the reaerator control signal varies continuously over the period in order to minimise the effects of all the disturbances and the instream Do level oscillates only slightly around the reference level, indicating the efficacy of the control system design at least from the simulation viewpoint.

5. An application of instream aeration in the River Cam

The possibility of maintaining automatic control over water quality in a river system is of immediate interest to the Great ouse River Division of the Anglian Water Authority following the report of the GORD working party on dissolved oxygen in the Cam (1975). The steadily deteriorating situation in the river downstream of Baits-Bite appears to be due to the combined effects of unsatisfactory sewage effluents caused by overloading at Cambridge sewage works, pumping station overflows, and finally, the marked diurnal variations in Do that appear in the reach during prolonged periods of dry, sunny weather and are probably due to the presence of large algae populations that become established in the nutrient rich environment downstream of the sewage outfall (Beck and Young 1975). The influents tend to depress the overall DO level and this, combined with the large diurnal variations, provide a DO level at night which is sometimes insufficient to support fish life. Fish mortalities and pollution have occurred in the reach from Baits-Bite to Bottisham - the reach of the Cam studied by Beck in 1972 .

The planned expansion of the sewage works will not be operational until 1978 and the recommendation of the working party was, therefore, to alleviate the short term problem by installing artificial aerators in the Cam downstream of Baits-Bite. Since the transient violations of water quality are of importance in this problem the dynamic model may be used to assess the effect of the aerators and develop a possible control strategy.

The discrete dynamic BOD-DO model for the Cam described in section 2 was based on the mid-day Do levels. In the present study, therefore, it was necessary to re-estimate the model using the 7 am Do values which represented approximately the daily minimum of the diurnal cycle. The model obtained from this analysis was as follows for mean $\mathrm{Vm} / \mathrm{Q}_{\mathrm{k}-1}=0.9$ days 


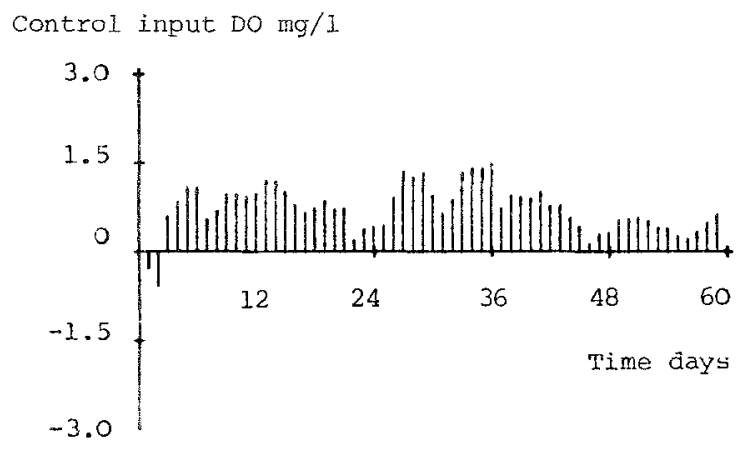

Downstream Do mg/1

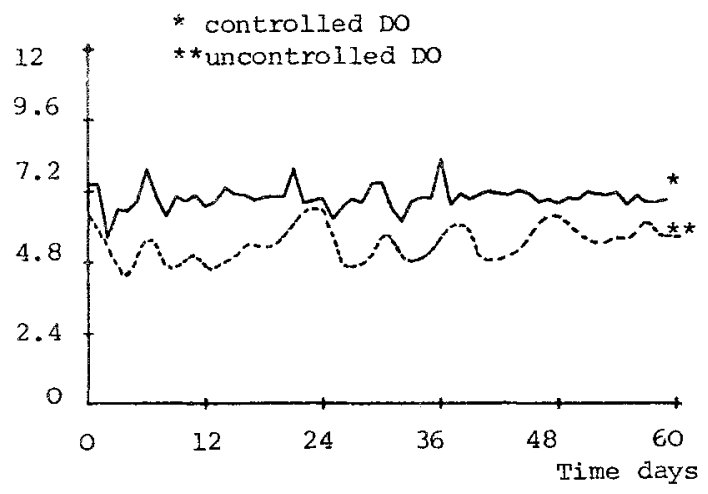

Figure 5 Downstream Do level and Control signal using 1973 summex data on the River Ouse. 


$$
\begin{aligned}
x_{k} & =\left[\begin{array}{cc}
0.32 & 0 \\
-0.41 & 0.02
\end{array}\right] x_{k-1}+\left[\begin{array}{cc}
0.41 & 0 \\
0 & 0.05
\end{array}\right]\left[\begin{array}{l}
L_{k-1} \\
c_{k-1}
\end{array}\right] \\
& +\left[\begin{array}{c}
0.14 \\
0.21
\end{array}\right] s_{k-1}+\left[\begin{array}{c}
0 \\
0.73
\end{array}\right] c_{s_{k-1}}
\end{aligned}
$$

On the basis of the above model a feedback-feedforward control scheme similar to that for the Ouse was developed, in which the controller gains were found to be

$$
\begin{aligned}
& k_{1}=0.003 \\
& k_{2}=-1.03 \\
& k_{3}=-0.05
\end{aligned}
$$

An additional facility is included in the Cam controller so that the control only operates when the dissolved oxygen level falls below the reference level of $6 \mathrm{mg} / \mathrm{l}$. This is an obvious practical requirement since it is unnecessary to operate the aerators when high Do levels exist.

The controller was applied initially to the Cam Model using the 1972 summer data. Figure 6 shows the sustained high levels of bo throughout the summer and the control signal or aerator input remains zero for much of the time and only $1 \mathrm{mg} / 1$ of dissolved oxygen was required after day 46 . In order to test the control scheme under more difficult conditions, an additional effluent loading of $5 \mathrm{mg} / 1$ of BOD was input into the reach model and a typical simulation run with control under these conditions is shown in Figure 7. The controlled response is reasonably constant at $6 \mathrm{mg} / 1$ but, as with the Ouse example, the discrete control law cannot counteract all the disturbances and some minor oscillation about the reference is obtained. The control signal shows an input of oxygen over the entire period and this increases to a maximum of about $3 \mathrm{mg} / 1$ after day 45 at the end of the sunny period. The control input during the sunny period is reduced since there is a net input of DO from the photosynthetic and respiratory effects.

The analysis indicates that, during poor quality conditions, up to $3 \mathrm{mg} / \mathrm{l}$ of additional downstream dissolved oxygen will be required. On the basis of WRPL tests on the proposed aerator equipment three aerators would be required to provide the additional Do and so help to prevent the possibility of a fish kill. It is clear, however, that at certain times less reaeration is required and one or two aerators would suffice to maintain satisfactory instream Do. It is necessary, therefore, to consider how the control system can be modified to allow for the efficient and flexible operation of the three aerators.

The aerator efficiency $R$ is related to the power rating $P$ by the following relationship 


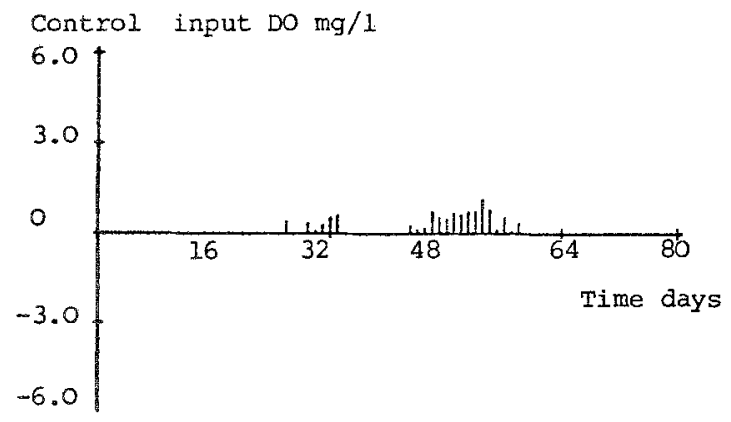

Downstream DO mg/l

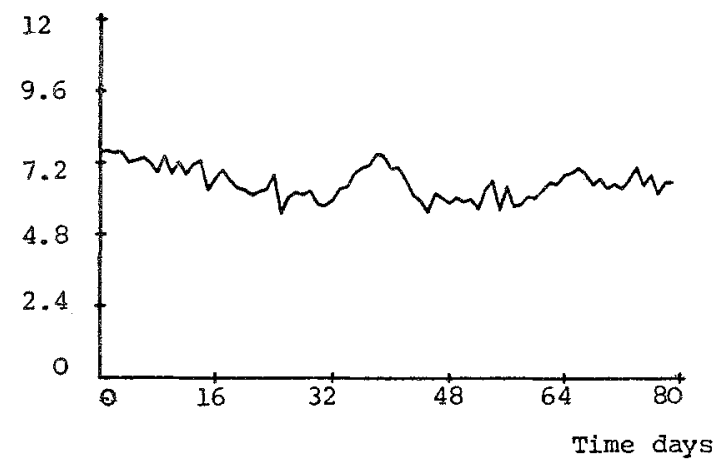

Figure 6 Downstream DO level and associated control input for the Cam over Summer 1972. 

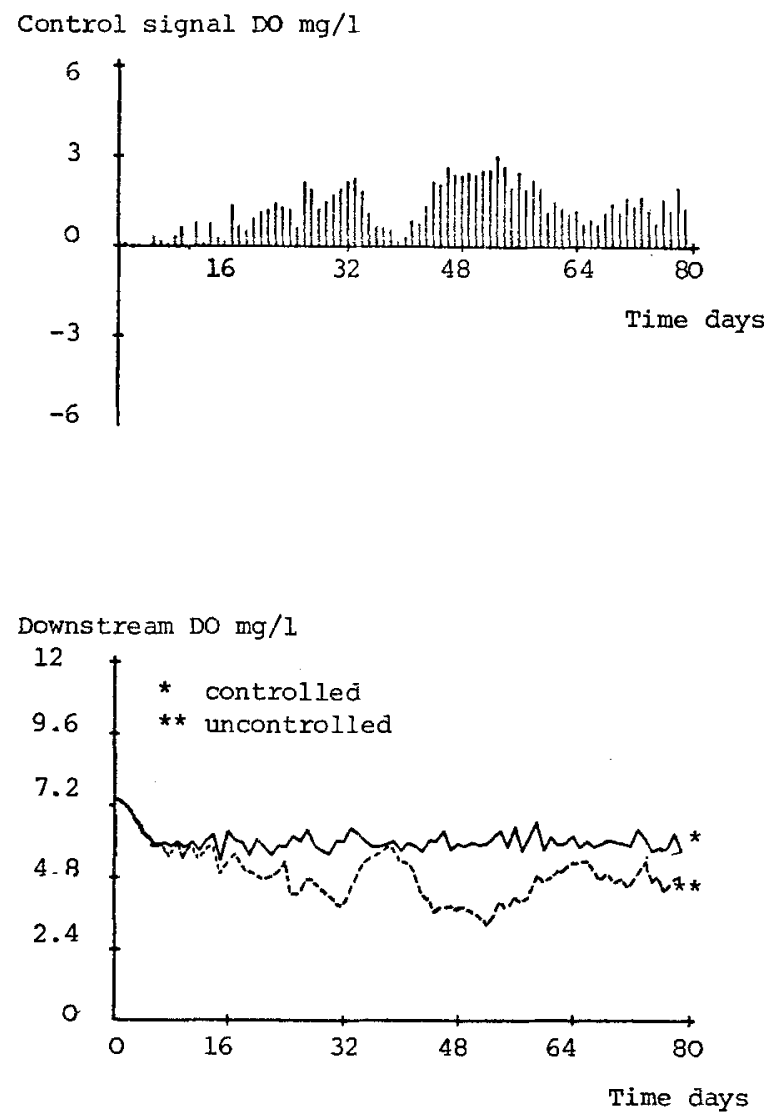

Figure 7 Controlled downstream Do for River Cam given additional effluent loading. 

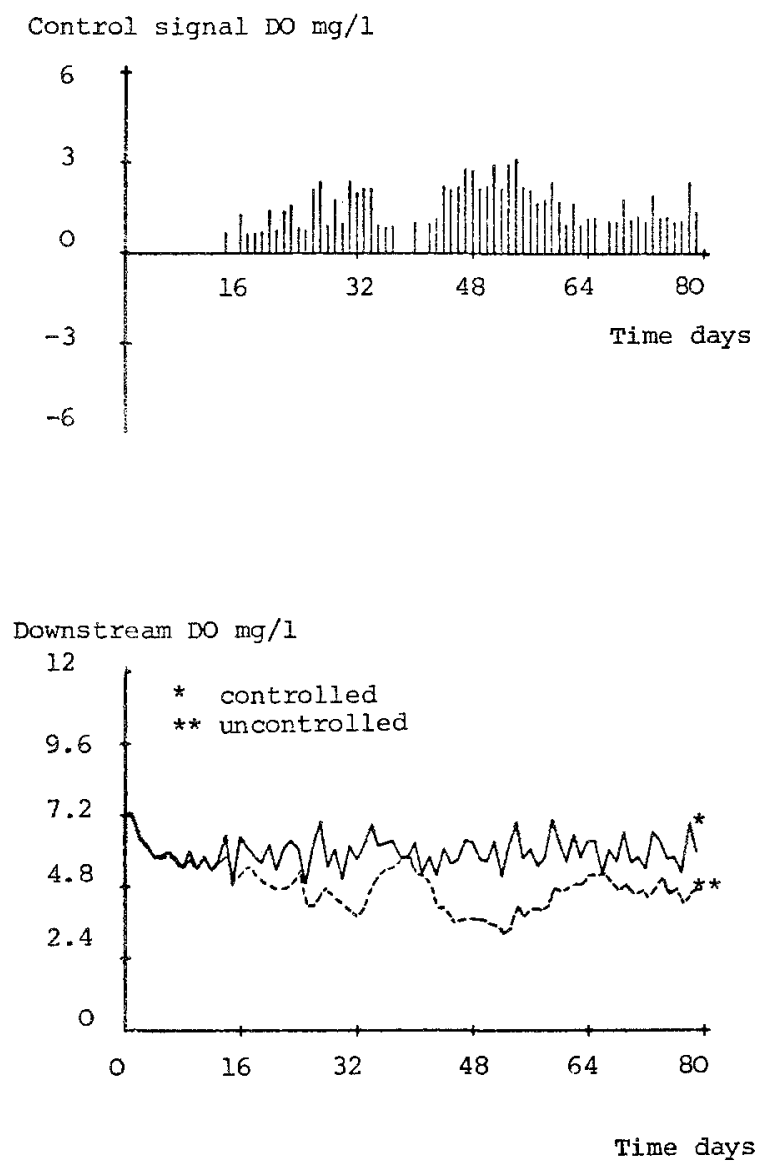

Figure 8 Control using three aerators. 


$$
R=\frac{k\left({ }_{s}-C\right)}{P}
$$

where $C_{S}-C$ is the saturation oxygen deficit and $\mathrm{k}$ is a coefficient of aeration. At the low flow conditions in the $\mathrm{Cam} \mathrm{k} / \mathrm{P}$ is calculated from the manufacturers' literature and the WPRL trials as 0.18. The siting of the aerators on the river is likely to influence their performance since if the aerated water stream from an upstream aerator passes into the intake of a second aerator, the efficiency of the second aerator will be low. The aerators should, therefore, be separated by a suitable distance to ensure adequate mixing. Even so, the saturation deficit will be successively smaller at the second and third aerator and this effect can be assessed using equation (22): at each aerator the new saturation deficit is determined and the oxygen level increases in a stepwise fashion down the river each time with a successively smaller step.

The theoretical control signal shown in Figure 7 does not contain this kind of stepwise operation and a modified control signal including the aerator efficiency factor is determined such that, at each step, the best use of the available aerators is achieved. In effect, a three level control signal is used consistent with the three levels available for the aeration equipment. This modified control scheme is shown in Figure 8 and a clear stepwise input is obtained. Of course, the step size does vary slightly according to the saturation deficit which itself varies with temperature: but nevertheless the three level control action still maintains an adequate DO level in the river despite the obvious quantisation error introduced by the use of only three discrete levels of control.

6. Conclusions

This preliminary study has shown that the application of aerators in the Cam appears to be a satisfactory solution to the problem of maintaining safe Do levels in the river. The Great Ouse River Division have now purchased three aerators for use in the River Cam and it is proposed that the control system be evaluated on-line.

The application of relatively simple feedforward-feedback controllers to the problems of water quality control immediately downstream of major sewage discharges is considered a highly practical approach and one that will become increasingly attractive as sewage plants become more flexible.

In addition, the application of the recursive algorithms to the estimation of model parameters provides models which are statistically efficient and which may be estimated from field data, data that is often corrupted by high levels of measurement noise. 


\section{References}

Beck, M.B., and Young, P.C., (1975), Identification and Parameter Estimation of DO-BOD models using the Extended Kalman Filter, CUED/F - CONTROL/TR93 (1975). University of Cambridge. Engineering Department.

Beck, M.B., and Young, P.C., (1975), A Dynamic Model for BOD-DO Relationships in a Non-Tidal River, Water Research, to be published 1975.

Box, G. and Jenkins, G.M., (1970), Time Series Analysis Forecasting and Control, Holden Day.

D'Azzo, J.J., and Houpis, C.H., Feedback Control Analysis and Synthesis, McGraw Hill, 1966.

Dorf, R.C., Time Domain Analysis and Design of Control Systems, Addison-Wes1ey, 1965 . Report of the Working Party on Dissolved Oxygen, Artificial Aeration of the River Cam, Anglian Water Authority, 1974.

Takahashi, Y. Rabins, M.J., Auslander, D.M., Control and Dynamic Systems, AddisonEsley, 1970 .

Young, P.C., (1970) Automatica, Vol.7, No.2 p 271.

Young, P.G., Shellswell, S.H., Neethling, C.G., (1971), Tech. Report., Dept. of Engineering, University of Cambridge, CUED/B - CONTROL/TR16.

Young, P.C., and Beck, M.B., (1974). The Modelling and Control of Water Quality in a River System, Automatica Vo1.10 No.5 pp 455-468.

Young, P.C., and Whitehead, P.G., (1974). 77 Recursive Approach to Time-Series Analysis for Multivariable Systems, Proc. IFIP Working Conference on Modelling and Simulation of Water Resource Systems, Ghent, Belgium (July/August), North Holland, Ams terdam.

Whipple, W.N., Coughlan, F.P., and Yu, S.L., Instream Aeration for Polluted Rivers, ASCE, JSED, October 1970 .

Whitehead, P.G., and Young, P.C., (1974), A Dynamic Stochastic Model for Water Quality in part of the Bedford Ouse River System, Proc. IFIP Working Conf. on Modelling and Simulation of Water Resources Systems. Ghent. Belgium (July/ August) North-Holland. Amsterdam. 